\title{
Shoulder Strain Caused by Mammary Prostheses an Experimental Comparison of Different Forms of Epicutaneous Prostheses
}

\author{
Andreas Hackethal Karsten Münstedt \\ Department of Obstetrics and Gynecology, University Clinic Giessen, Germany
}

\section{Key Words}

Breast cancer - Epicutaneous breast prostheses .

Shoulder pressure

\section{Summary}

Background: In the case of breast cancer, removal of the breast can not always be avoided. The use of external prostheses, however, can lead to discomfort for the patients through shoulder pain and muscle hardening. It can be assumed that this is caused by strain on the shoulder due to the weight of the prosthesis. This study was to identify the possibilities to objectively assess patients' complaints associated with this type of supportive treatment. Subjects and Methods: In this pilot study, varying types and sizes of prostheses were tested on male subjects, quasi as if they were women amputated on both sides. The strain caused by the prostheses and distributed via the straps of the brassiere were measured by electronic pressure sensors and statistically evaluated. Results: Weight-reduced prostheses significantly decreased the resulting average pressure amplitude $(p<0.01)$ compared to normal weight prostheses. Furthermore, heavy contact prostheses, which are attached to the chest wall, have a significant advantage $(p<0.01)$ compared to normal prostheses of the same size. Moreover, evidence was found that contact prostheses have advantages with respect to pressure on the shoulder during physical exercise, e.g. running. Conclusion: Currently, weight-reduced contact prostheses present optimal treatment after breast amputation.

\section{Introduction}

Apart from the possibilities of breast-preserving and reconstructive surgery, supplying women with epicutaneous prosthetics still plays an integral role in the medical care of female patients after mammectomy. For women dependent on epicutaneous provisions, optimal counselling is of paramount importance in order to supply them with the best possible prosthesis. Deciding on a specific prosthesis depends on different factors, many of which are completely subjective (e.g. comfort, naturalness).

To date, studies only focussed on subjective complaints of patients. Therefore, the aim of this paper is to investigate the shoulder strain through objective measures, thereby assessing possible advantages of epicutaneous prostheses, especially regarding adhesive appliances.

\section{Subjects and Methods}

The pressure beneath the straps of the brassiere was measured by pressure sensors (9800 series, consisting of $8 \times 16$ single sensor fields; Tekscan, South Boston, MA, USA) placed beneath the straps. Subsequently, the sensors lying directly beneath the straps were identified. In order to simulate the strain generated by movement, the measurements were taken on a treadmill (Trimline 7150.3E; DF Hebb Industries, Tyler, TX, USA) during walking and running. Thus, it was possible to generate a time-pressure curve for each side, whereupon maximum and minimum values were obtained by administering periodical oscillations. The oscillation amplitude was calculated and correlated to either walking or running.

In order to compare different forms of breast prostheses, the subjects were all male volunteers (simulating bilaterally ablated female patients). Subject 1 (age 30, $178 \mathrm{~cm}, 82 \mathrm{~kg}$ ) was given a corsage size 90B (brand Virginia; Amoena, Raubling, Germany) and tested prostheses of size 7. Subject 2 (age 34, $185 \mathrm{~cm}, 78 \mathrm{~kg}$ ) was given a bra of the same trademark size $90 \mathrm{D}$ and prostheses of size 10 . Each subject underwent 9 iterations. Each result represents the mean value of $>50$ individual measurements. Measurements were repeated to assure accuracy. Characterisation of the prostheses is shown in table 1. Statistical analyses consisted of Student's t-test for independent samples.

Results

No significant differences between one-layer and two-layer prostheses regarding shoulder strain were found.

\section{KARGER}

Fax +497614520714

Information@Karger.de

www.karger.com

\section{(c) 2009 S. Karger GmbH, Freiburg}

Accessible online at:

www.karger.com/brc
Prof. Dr. Karsten Münstedt

Zentrum für Frauenheilkunde und Geburtshilfe

Universitätsklinikum Gießen und Marburg

Klinikstraße 32, 35392 Gießen, Germany

Tel. +49 641 99-45200, Fax -45139

k.muenstedt@gyn.med.uni-giessen.de 
Table 1. Characterisation of the tested prostheses

\begin{tabular}{llcc}
\hline Name & Type of prosthesis & Weight size 7, g & Weight size 10, g \\
\hline Tria II & two-layered prosthesis & 456 & 732 \\
Tria basic & $\begin{array}{l}\text { one-layered prosthesis } \\
\text { weight-reduced two- }\end{array}$ & 448 & 710 \\
Tria II light & $\begin{array}{l}\text { layered prosthesis } \\
\text { weight-reduced one- } \\
\text { layered prosthesis } \\
\text { Tria basic light }\end{array}$ & 346 & 552 \\
Tria contact & $\begin{array}{l}\text { pormal weight contact } \\
\text { prosthesis } \\
\text { weight-reduced contact } \\
\text { Tria contact light }\end{array}$ & 490 & 511 \\
& prosthesis & 372 & 751 \\
\hline
\end{tabular}

Fig. 1. Contact prostheses compared to normal prostheses during running $(* \mathrm{p}<0.05)$.
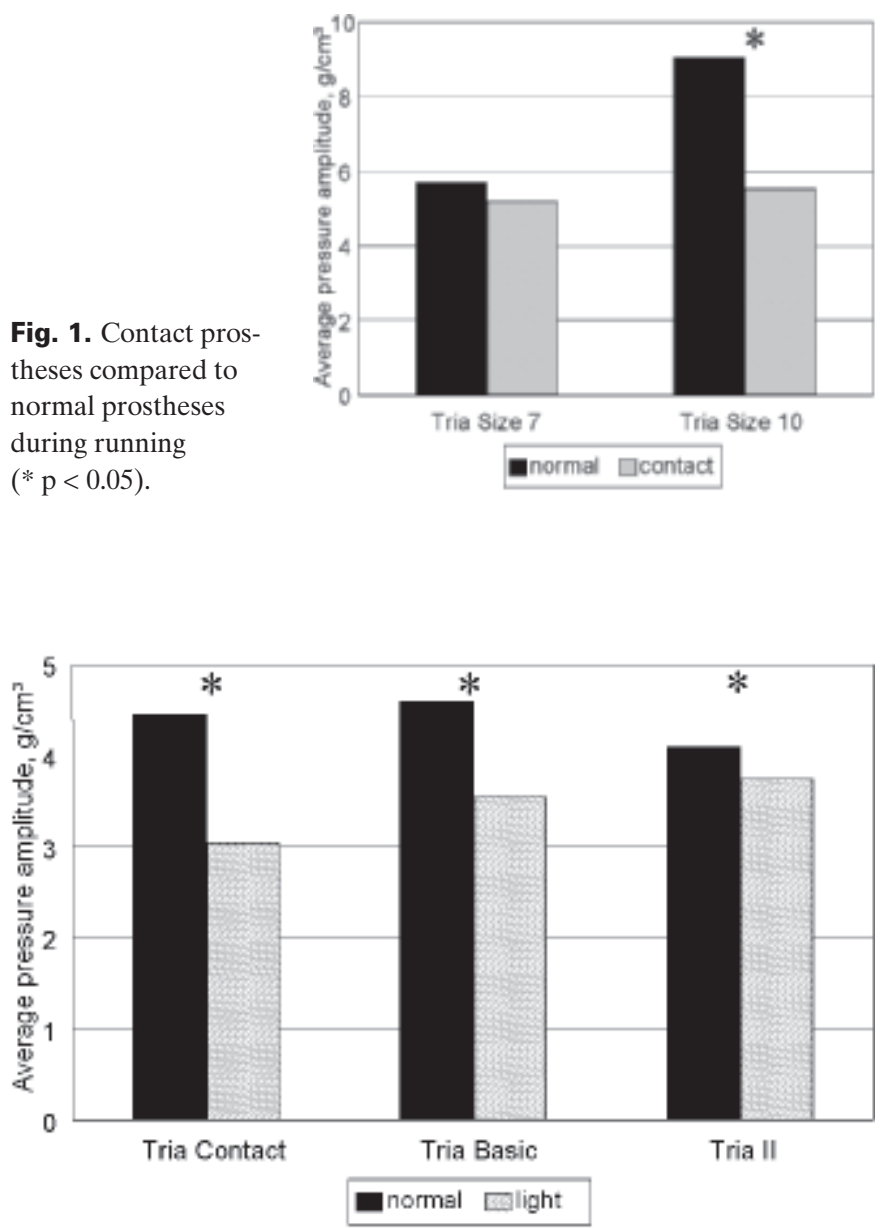

Fig. 2. Light weight prostheses compared to normal weight prostheses during walking. The results are shown for 3 types of size 7 prostheses $\left({ }^{*} \mathrm{p}<0.05\right)$.

Contact adhesive prostheses of size 10 showed significantly smaller pressure amplitudes during running compared to normal prosthe$\operatorname{ses}(\mathrm{t}=3.67, \mathrm{p}<0.005$; fig. 1$)$.

It was shown that lower weight led to a lower pressure amplitude in both conventional and adhesive prosthetics. Exemplary data are shown in figure 2. Even though the small sample size does not allow generalisations, it can still be said that both subjects reported the highest comfort wearing light contact prostheses.

\section{Discussion}

The results clearly show that light adhesive prostheses cause the least pressure amplitudes beneath the straps of the brassiere. These can be viewed as a correlative of the shoulder discomfort reported by patients, as it can be assumed that higher pressure amplitudes lead to microtraumata within the underlying tissue in these regions during motion. Both the adhesion of the prosthesis to the skin as well as the weight reduction absorbs a part of the pressure. These findings adequately explain patients reporting lesser shoulder complaints after the transition to adhesive prostheses and explain why most women in the aforementioned studies preferred self-adhesive breast forms [1-3].

It may be concluded from studies on reduction mammoplasty and discomfort caused by too heavy breasts that better external breast prostheses may also positively influence lung function and the vegetative nervous system [4-6]. Thus, weight-reduced, self-adhesive breast forms should be considered as the standard care for women after mammectomy without immediate breast reconstruction, especially in women with larger breasts.

\section{Acknowledgement}

We would like to thank Amoena GmbH, Raubling, Germany, as well as Dr. Klaus J. Dimde and Mr. Phillip Grant for their support.

\section{Conflict of Interest}

This study was supported by Amoena GmbH, Raubling, Germany. Apart from this support the authors have no conflict of interest to disclose.

\section{References}

1 Münstedt K, Milch W, Reimer C: Breast forms after mastectomy - patient's issues. Support Care Cancer 1995;3:428-431.

2 Münstedt K, Schüttler B, Milch W, Sachsse S, Zygmunt M, Kullmer U, Vahrson H: Epicutaneous breast forms. A new system promises to improve body image after mastectomy. Support Care Cancer 1998;6:295-299.

3 Thijs-Boer FM, Thijs JT, van de Wiel HB: Conventional or adhesive external breast prosthesis? A prospective study of the patients' preference after mastectomy. Cancer Nurs 2001;3:227-230.

4 Lee YA, Kikufuji N, Tokura H: Field studies of inhibitory influence of skin pressure exerted by a body compensatory brassiere on the amount of feces. J Physiol Anthropol Appl Human Sci 2000;4:191-194.

5 Miyatsuji A, Matsumoto T, Mitarai S, Kotabe T, Takeshima T, Watanuki S: Effects of clothing pressure caused by different types of brassieres on autonomic nervous system activity evaluated by heart rate variability power spectral analysis. J Physiol Anthropol Appl Human Sci 2002;1:67-74.

6 Sood R, Mount DL, Coleman JJ, Ranieri J, Sauter S, Mathur P, Thurston B: Effects of reduction mammaplasty on pulmonary function and symptoms of macromastia. Plast Reconstr Surg 2003;2:688-693. 